\title{
Academic Developers using narrative to support our professional development.
}

\author{
O'Farrell, Ciara ${ }^{a} *^{1}$ and Fitzmaurice, Marian ${ }^{b}$ \\ ${ }^{a}$ Trinity College Dublin; ${ }^{b}$ Dublin Institute of Technology
}

Keywords: narrative; reflection; support; professional development; affective domain; emotion; sustainability; network.

This article illustrates how narrative can be used as a tool to support those of us engaged in academic practice. It stems from a programme conducted with members of the Educational Developers of Ireland Network (EDIN) where the authors used narrative as a framework to critically reflect on our roles and practices as academic developers. Given the rise of managerial values and the drive for sustainability that dominates the current higher education context, this paper argues that academic developers need to find ways to sustain our-selves in our work and to reclaim the emotions and values that define us, even if they are not reflected back to us by our institutions. The process also resulted in very practical outcomes that focused on sustaining and strengthening our network. The authors propose that this approach to narrative not only enhances collegiality and support but can help steer the sustainability of academic development networks like EDIN.

\section{Introduction}

\footnotetext{
${ }^{1}$ Corresponding author. Email: ciara.ofarrell@tcd.ie
} 
This paper explores the use of narrative as a means of supporting academic developers in our own professional development. It stems from a short programme offered to the Educational Developers of Ireland Network (EDIN) by the authors, themselves members of the network. An integral part of the role of the academic developer is to support academics, but in the context of underfunded and understaffed units, the authors wondered if academic developers like us were neglecting our own professional development and if we were failing to support ourselves? We thus developed a monthly forum where participants used narrative as a framework to focus our experiences as academic developers, critically reflecting on our roles, the values and emotions that guide us and the challenges we face in a context where the ethos of care in relation to students and staff can be argued to be eroding. Through making time for our own professional development and using narrative to voice and explore the affective dimension of our roles in a safe and structured environment, our group found a renewed collegiality and peer support which we drew strength from. But the process also resulted in very practical outcomes focused on sustaining and strengthening our network. This paper will explore the process and the outcomes of the narrative programme.

Ireland is currently in the grips of a recession that has rocked our economy. Irish universities and institutions are facing a state of economic crisis and a crisis of morale. In 2009 the Employment Control Framework was imposed on the higher education sector which placed a moratorium on recruitment and promotions. In 2012 this is still in place. Thus, while student numbers are rising, staff numbers are falling and most of us work in shrinking learning and teaching centres with smaller budgets and increased workloads. Concerns over the sustainability of our own network are also increasingly to the fore as our initial funding has ended and we are operating on a very limited and finite budget. Thus, the background that defines and challenges academic development in Ireland affects universities and institutions, academics and academic developers and, in this case, a network of academic developers. In the drive for sustainability that dominates our current Higher Education context, this paper argues that academic developers need to find ways of sustaining our-selves in our work and of unpacking and drawing on the values and emotions that define us, even if they are not reflected back to us by our institutions. The authors propose that this approach to narrative as a form of collective reflection might be used as a means to promote self care among academic developers in networks or teams, to enhance collegiality and professional development, or to drive sustainability of existing networks like EDIN.

\section{Narrative as a reflective tool and methodology}

Reflective practice is widely discussed in the learning and teaching literature and commonly used as a model for continuing professional development in higher education 
(Clegg, Tan, \& Saeidi, 2002). Rooted in Dewey's (1933) and Schon's (1983, 1998) presentation of reflection as a deliberate way of thinking that leads to change in action, it typically involves the analysis of critical incidents, the unpacking of knowledge from that analysis and the formation of new knowledge that can then be applied professionally (Davis, 2003; Murphy, Halton and Dempsey, 2008; Pedro, 2005). Criticisms of this approach are that it is often conceived as a cognitive construct and tends to operate at the personal level. However, the authors were interested in exploring the affective dimension of our roles through reflection that was shared with others. Hung (2008) points to definitions of reflection which support the notion of reflection being a cognitive construct. These include Hatton and Smith's (1995) notion of 'deliberate thinking about action with a view to its improvement' (p. 52); Daudelin's (1996) focus on the 'highly personal cognitive process which happens in the mental self' (p. 39); and Osterman and Kottkamp's (2004) description of the reflective strategy that provides professionals with 'opportunities to explore, articulate, and represent their own ideas and knowledge' (p. 16). Less is written about the role of the affective dimension in reflection, although Mezirow's transformational change - 'the process of becoming critically aware of how and why our presuppositions have come to constrain the way we perceive, understand, and feel about our world' (1990, p. 14) - may be seen as inherently an affective endeavor.

Narrative is typically a reflective story with a beginning, middle and end that can be told from one or more perspectives, although narratives can also be centred on an incident or 'topic centred' (Reissman, 1993 quoted in Jones). The significance of narrative in higher education research is that personal stories are brought to the fore, illustrating the complexity of academic practice, but its strength also lies in 'its ability to present the human side of education to illuminate some of the intensely personal and individual stories that are, nonetheless, recognisable' (Jones, 2011, pp. 115-116). As a reflection of the authors' individual voices, purposes and perspectives, narratives can act as a starting point for critical reflection. The articulation of the significance of one's personal experience is thus the core to the process as it is through the narrative that we come into contact with people engaged in the process of interpreting themselves (Josselson, 1995). However, Zeichner's (1994) distinguishes between reflection as private activity to be pursued in isolation by individual teachers, and reflection as a social practice involving communities of teachers. Our narrative process allowed us to actively engage in collective dialogue on both the 'social and moral implications of different perspectives and standpoints encountered' (Ellis and Bouchner, 2000, p.748) and encouraged us to reflect on the feelings and emotions that informed and moulded these perspectives. Narrative research incorporates many forms such as autobiography, life stories, life histories and biography, and 'has energized the study of an array of topics social movements, organizations, politics and other macro-level processes' (Riessman, 2008). Although analytic studies of narrative 'remain a field in the making' researchers 
using narrative as a tool have a critical and crucial interest in making sense of their experiences (Chase, 1995. p.651). The authors felt that a narrative approach would thus enable us to explore both the cognitive and the affective aspects of the academic developer.

\section{The study}

The authors invited Educational Developers in Ireland Network (EDIN) members by email to partake in the Narrative Programme. While there are over one hundred members in the network, they are dispersed across the country and internationally. Those interested had to be able to attend four half-day sessions in Dublin. We had a number of requests to attend two or three sessions, which were declined as we wanted a sense of trust to be established in the group and felt that less than full participation might hinder this. Eight participants signed up to the full programme. Two Universities and four Institutions of Technology were represented in the group. The programme was divided into monthly workshops, focusing on specific themes: identity of the academic developer; enhancing academic development practices to ensure impact; leading on curricular and organisational development; and disseminating good practice within our network.

We shared Taylor's empirical study of adult education with the group (Taylor, 1998) in an attempt to depict the environment we hoped to establish: (a) that adult educators need to be trusting, empathetic, caring, authentic, sincere, and demonstrate a high degree of integrity; (b) that an emphasis should be placed on personal selfdisclosure; (c) that it is critical to discuss and work through emotions and feelings prior to engaging in critical reflection; and (d) that feedback, self-assessment, and self-dialogue are all central to the process. At the beginning of each session we used brief writing prompts to start the process of narrative writing where participants wrote individually but from a shared set of prompts. The ideas written about were then discussed in small groups providing further opportunity for ideas and issues to be shared. We then moved on to writing a narrative which could take various guises: a critical reflection on a general experience, a focus on a particular incident, or a story. These narratives were then discussed collectively, in an attempt to use the personal as a springboard, or like a camera, 'zooming out' (Watson \& Wilcox, 2000, p.61) to include other perspectives. Over the month writers revisited and re-considered their narrative, refining or adding to it as necessary. In the final hour of the workshop two of the participants read to the group a pre-written narrative of their choice which was followed by a discussion of both the narrative and the themes emerging from it, along with any implications for practice.

Narrative enquiry is grounded in close study of the particular, and the procedure for implementing the research was gathering data through the collection of these written 
narratives which were then analysed. Narratives do not speak for themselves and when used for research purposes they require close interpretation. Thus, the work of the researcher is not completed when the stories are collected, and systematic purposive analysis is required (Atkinson \& Delamont, 2006). Despite the growing interest in narrative within the social sciences, there is no single analytical approach or list of procedures that is generally recognised as representing the narrative method of analysis (Elliott, 2005). Lieblich, Mashiach and Zilber (1998) suggest that the wide variation in approaches to narrative research can be described using two dimensions, a focus on the content or on the form of narratives. In terms of our research, analysis was conducted with a focus on the content of narratives to elicit the common themes that emerged. Participants in the group sent us their prompts and narrative reflections for this research. In all fifty four narratives from eight participants were received. In analyzing the narratives we chose a 'thematic analysis' method that focused on identifying and describing both implicit and explicit ideas' (Namey, Guest, Thairu \& Johnson., 2007, p.138). Having read and cross-checked all narratives, we identified emerging themes and establishing patterns using a data-driven approach (looking for key-words, trends and themes in the narratives to help outline the analysis). We then re-read all the narratives, focusing our attention on drawing themes from the rich, descriptive detail of the qualitative data, in an attempt to form a representation of the participants' collective experience of both the content of their narratives and the narrative process itself.

\section{Findings and discussion}

Three significant themes emerged from our analysis: (i) the challenges of the present context within the Higher Education contest; (ii) the importance of acknowledging the affective; and (iii) the capacity of the narrative process as a tool for development.

\section{(i) On challenges of the present context}

The struggle of the international academic development field with implications of role and identity in the age of 'supercomplexity' (Barnett, 2000) and the refining notion of 'being' an academic/academic developer as the academic landscape changes is mirrored in our narratives:

It always felt like working in isolation and looking in from the fringes, and being outside the loop in terms of communication.

Our unit has shrunk so much, being an academic developer is even more isolating than it was. 
Having no visibility within my school was also a big challenge - this made the challenge of integration and creating identity all the more difficult.

There are always those who see us a 'training centre', as being focused on the remedial, and [name of institution] has done little to help change these perceptions.

These extracts point to a sense of isolation for the academic developer and reflect the struggle with role and identity that that has been discussed in the literature for a decade and longer. They testify to the difficulty of the perception that Teaching and Learning is not academic but rather a technique anyone can pick up with some training (Weiner, 2007), and they speak of our professional roles and the contradictions that arise from competing identity claims. Despite Handal's argument (2008) that one's professional identity should correspond to the ethos of the academy, our narratives showed that the expectations the institution holds of the academic developer can sometimes be at odds with the academic development unit itself and our perceived identities within it. Finally, these extracts point to the practical issues of trying to continue our work and outreach with less staff and less funding. As one participant wrote:

Due to the economic decline and the demise [...]I have no staff, we are standing still. So, the challenges I am personally facing is (a) demise of [...] funding, (b) competition for scarce resources, (c) due to lack of human resources, time for reflection, development, and facilitation of workshops has disappeared. This paints a bleak picture.

Weimer noted in 2007 that Teaching and Learning centres were so poorly funded and understaffed that committed academic developers were in danger of burning out (Weimer, 2007). The economic situation in Ireland has deteriorated remarkably since then. Our narratives discussed broad issues such as our country's economic decline and the commercialisation of the university but also the related challenges of visibility, perception, or low staff morale that is replacing self value in this complaint culture (Anderson, Johnson \& Saha, 2002; Churchman 2006 ):

Morale is low all around me. I worry about my job too but it's like we always have to be the cheery ones, supporting others. And support roles are always first in the firing line.

I end up feeling like a 1950's 'housewife' spending my 'allowance' every time I run a workshop. The fact that we are not seen to be bringing in funding is deeply problematic as we are perceived as spending money that 'others' earn. In a compliance-based culture we are in danger of been seen as profoundly non- compliant.

In these extracts, the writers point to the expectation on academic developers to support while questioning its financial cost. And they indicate the lack of support felt by 
academic developers themselves. Much has been written internationally about the commercialisation of university education and the autonomous institution's transformation into a business-like operation run in a competitive environment, where academic integrity and peer regulation have been replaced with managerial governance and biometric measurements (Anderson, 2006; Churchman, 2006; Robertson, 2002). Lynch reads into this context an intensification of 'carelessness' which she sees as being at odds with the moral imperative on the academic to care and support (Lynch, 2010, p.63). Universities have become overtly 'managed' in a culture of marketisation where performance is measured by quantifiable, but 'blunt' indicators (Anderson, 2006). Our narratives pointed to a need to find more appropriate indicators:

I really feel it's important to fight the context which seems to propel me towards a value-less community, where all that counts is how many people pass through my doors.

What is my future as an academic developer within a system that is defined solely by what is measurable? And if I want to stay in that system playing by these rules, am I willing to yield the values that define my identity as an academic developer?

These quotes ask whether academic development work can be adequately measured in such a system given the lack of holistic modes of evaluation, and they question the place of the academic developer in such a system. And while our narratives not go so far as to find more holistic ways of measuring our value, they did express a desired return to the values that led many of us into academic development in the first place, and stressed the importance of upholding these values while working in an increasingly more corporatised and competitive environment.

\section{(ii) On acknowledging the affective}

Narratives structure the past into a meaningful communication and these stories can illustrate frustration, pressure, fatigue, change, success and joy (Jones, 2011). Over the course of our programme our narratives became more reflective and personal as a sense of trust developed in the group. We began to write more openly about our fears, our self-doubting and our frustrations:

I think I hide the emotional aspects of my role, if I'm perfectly honest. I don't want to be seen by other academics as 'woolly'. Too many have that impression of us already. I deliberately focus on the scholarly and academic when describing my role. But yet I have developed many professional relationships with academics as a result of my work with them where discussion and reflection on the challenges of our roles directly address the emotional.

I anticipated that my role would have an emotional aspect but had little idea of the extent to which it I would feel the need to conceal it in my institutional context. 
Academic developers are rightly expected to be both professionally and pedagogically competent, but these extracts show that we are not inclined to voice the role of the personal in connecting with those we support or the 'emotional knowledge' inherent in our role (Zembylas, 2007, p. 374), lest it be viewed by the academy as 'woolly'. Peseta notes that academic developers rarely write of how our work 'feels' and that the full force of our narratives is absent because we hide its emotions:

We often write, too, with a worry that this difficulty speaks only of selfindulgence, as if the pain and hurt we experience as developers ought to be contained so as not to spill over into our practice and relationships proper. And we ask ourselves whether these are useful stories - whether they are stories worth telling, worth asking others to engage with, worth putting ourselves on the line for. (Peseta, 2007, p.17.)

We posit that the confined and safe environment of our programme acted as a conduit to experimenting with voicing the affective domain, of acknowledging the heart as well as the head, and of giving our stories worth. As a participant wrote:

There is place for developing skills and competencies, but there is a need to create spaces where the emotional and ethical dimension of the work is considered.

And so within this context, we began to voice a need to support and nurture our 'selves' more:

We need to support our own emotional and intellectual needs - we are the oil on the wheels, the lubricant. Otherwise we will grow rusty and stop.

With this group, we could finally concentrate on what we can become in a context where we support and nurture each other, and that was incredibly motivating. We should try to voice this approach more in the network.

These excerpts express a realisation that academic developers too have needs, and that we need to support these needs and seek support for them. Participants of the programme began to focus on the EDIN network as a safe environment where we can support and nurture each other through professional development that acknowledges both the affective and the cognitive aspects of our role. The following section discusses how we used the narrative process as a tool to influence our own professional development as academic developers with the network.

(iii) On using the narrative process as a tool for development. 
While our narratives at first journeyed back to the values that inspired us to become academic developers, towards the end of the programme they began to look forward to consider how we can use narrative, as one participant put it, to 'nurture our thinking and enrich our practice.' However, to look forward we first had to question that network honestly:

EDIN can be a useful forum for discussion and reflection on our practice, yet this has not been the case of late.

There are plenty of members who would be happy to give their services to the group, but I feel a more structured request would benefit the group.

We can see here how our narratives began to take on a more constructive approach as we reflected as a group on the possibilities of affecting change in our network. Anderson et al refer to 'collegiality' as 'the type of interaction which prevails between academics themselves that includes professional sharing and advice, as well as social support and sociability.' (Anderson et al, 2002, p.47). This sense of collegiality is reflected in EDIN's mission that speaks of its members sharing creative, critical, collaborative and professional approaches in supporting teaching and learning. Our narratives began to give the mission life through their exploration of possible future paths for EDIN.

The small community of academic developers within the institution is disappearing as contracts are not renewed. And with that goes the support of our community in all its facets. The community that is EDIN is even more important than ever in this sense.

As we wrote and spoke about the role of EDIN in the current context, its importance began to re-emerge, as we can see from the above quote, and this propelled us to explore what we might do collectively to re-energise our network: regular meetings, more direct involvement in EDIN, partnerships, pooling of expertise and a quarterly publication were among the possibilities suggested. Programme participants also began to focus on the potential of narratives of practice as a tool for development:

As individual academic developers, our individual voices sometimes seem powerless. A unified national voice of academic developers gains some strength...

Why did narrative work? Because this sort of structured dialogue and reflection forces action and change and because we don't want to lose sight of what we value. Because we can inspire each other to lead, because we can see the gaps and find ways to fill them.

These excerpts show how the narrative process can help us take responsibility for our own professional development and to take advantage of the collaborative aspects of our networks, of the strength in numbers. They also speak of the potential of narrative to 'inspire' or look forward and positively influence our future in the way we want to: 
It was so empowering to be given the opportunity to reflect on and discuss our own professional development. Even though I value this type of forum and anticipated a positive outcome, what we achieved as a small group far exceeded my expectations.

Importantly, the narrative programme led us to make some real strides concerning the sustainability and future direction of our network, a process perhaps other networks could benefit from. Taylor has noted that 'it is the transformation within a group context that gives individuals more courage to initiate social change within new communities' (Taylor, p. 23). And indeed, as a result of the programme participants have made changes to the network. For example, we have disseminated our research at conferences, one of the participants has taken on the chair of the EDIN community and two others became committee members overseeing responsibility for EDIN's professional development programme. Members of our programme also helped secure government funding for EDIN to produce a forthcoming publication Emerging Issues 111: From Capacity Building to Sustainability written by academic developers, and supported through collaborative writing retreats and peer review days facilitated by one of the authors. In all these areas a strong emphasis has been placed by programme participants on promoting a network that is safe and welcoming, where its members can celebrate the affective dimension of our role, and request and partake in professional development that supports and nurtures our needs.

\section{Conclusion}

This article has illustrated how academic developers can use using narrative reflection as a professional development tool to self support and to strengthen communities or networks of academic developers. We have argued that the narrative process gave programme participants a framework to analyse what it means to be an academic developer, to explore its emotional intensity and the affective dimension of our roles in a safe environment, and to affect positive change in the community. We have shown how in our initial journeys of reflection, participants moved inward as we analysed our senses of selves as academic developers. However, in a process moulded by dialogue and reliant on the supportive engagement of others in the group, we reached a shared understanding of the current troubled context in relation to academic development and what resulted was not only a more deliberate sense of self but also a collective understanding of the values that drive our network. Our narratives took on a more constructive approach as we reflected as a group on the possibilities of effecting change in our network. The process thus resulted in very practical outcomes focused on sustaining and strengthening our network. The authors propose that this approach to narrative might be used effectively as a framework to promote self care among academic developers in networks or teams, to scaffold, renew or enhance collegiality and sustainable peer support in networks, or to focus on ways of driving their sustainability. 


\section{References}

Anderson, D., Johnson, R. \& Saha, L. (2002). Changes in academic work, implications for universities of the changing age distribution and work roles of academics (London, Department of Education, Science and Training.) Available online at: www.dest.gov.au/sectors/higher_education/publications_resources/summaries_brochures /changes_in_academic_work.htm (Note to reviewers:: I am trying to locate this article as the website has been moved. I am awaiting reply to an email)

Anderson, G. (2006). Assuring quality/resisting quality assurance: academics responses to 'quality' in some Australian universities, Quality in Higher Education, 12, 161-173.

Atkinson, P. and Delamont, S. (2006). Editors' Introduction: Narratives, Lives, Performances. In P. Atkinson and S. Delamont (ed) Narrative Methods Volume 1.London: Sage Publications.

Barnett, R. (2000). Realizing the University in the age of supercomplexity. Maidenhead: Open University Press.

Chase, S. E. (2005). Narrative inquiry: Multiple lenses, approaches, voices. In N.K.Denzin \& Y.S. Lincoln (Eds.) Handbook of qualitative research (3rd ed.) Thousand Oaks, CA: Sage pp. 651-679.

Churchman, D. (2006). Institutional Commitments, Individual Compromises: Identityrelated responses to compromise in an Australian university. Journal of Higher Education Policy and Management 28, 3-15.

Clegg S.; Tan J. and Saeidi S. (2002). Reflecting or Acting? Reflective Practice and Continuing Professional Development in Higher Education. Reflective Practice, 3, 131146

Daudelin, M. W. (1996). Learning from Experience Through Reflection, Organizational Dynamics 24, 36-49.

Davis, M. (2003). Barriers to Reflective Practice: The Changing Nature of Higher Education. Active Learning in Higher Education, 4, 243-255.

Dewey, J. 1933. How We Think: A Restatement of the Relation of Reflective Thinking to the Educative Process (1910), revised edition. Boston: Heath. 
Elliott, J. (2005). Using Narrative in Social Research. Quantitative and Qualitative Approaches. London: Sage

Ellis, C. \& Bochner, A. P. (2000). Autoethnography, personal narrative, reflexivity: researcher as subject, in: N. K. Denzin \& Y. S. Lincoln (Eds) Handbook of qualitative research (2nd edn) (Thousand Oaks, CA, Sage), 733-768.

Handal, G. (2008). Identities of Academic Developers: Critical friends in the academy? in Barnett and Di Napoli, eds. Changing Identities in Higher Education: Voicing Perspectives, Routledge: Oxen, pp.55-68

Hatton, N. \& Smith, D. (1995). Reflection in teacher education: Towards definition and implementation. Teacher and Teacher Education, 11, 33-49.

Hung, H. (2008). Teacher learning: Reflective practice as a site of engagement for professional identity construction. US-China Education Review, 5, 39-49.

Jones, A. (2011). Seeing the messiness of academic practice: exploring the work of academics through narrative, International Journal for Academic Development, $16,109-118$

Josselson, R. (1995). Imaging the Real: Empathy, Narrative and the Dialogic Self in Interview Studies. In R. Jollelson \& A. Lieblich (eds) Interpreting Experience: The Narrative Study of Lives. Thousand Oaks CA: Sage p. ix-xiii.

Lieblich, A. Mashiach, R.T. and Zilber, T. (1998). Narrative Research. Reading, Analysis and Interpretation. Thousand Oaks; London and New Delhi.

Lynch, K. (2010). Carelessness: a hidden doxa of higher education. Arts and Humanities in Higher Education. An International Journal of Theory, Research and Practice, 9, 5467

Mezirow, J. (1990). How Critical Reflection Triggers Transformative Learning, in J. Mezirow (ed.) Fostering Critical Reflection in Adulthood: A Guide to Transformative and Emancipatory Learning, pp. 1-20. San Francisco, CA: Jossey-Bass.

Murphy, M, Halton, C, \& Dempsey, M (2008). The Transfer of Reflective Engagement From Social Work Education Into The Workplace: A Study of The Value of Scaffolded Reflection. Irish Educational Studies, 27, 71-80.

Namey, E., G. Guest, L. Thairu and L. Johnson. (2008). Data Reduction Techniques for Large Qualitative Data Sets, in G. Guest and K. MacQueen (eds.). Pp. 137-161. Handbook for Team-Based Qualitative Research. Altamira Press:UK 
Osterman, K. P., \& Kottkamp, R. B. (2004). Reflective practice for educators: Improving schooling through professional development. Thousand Oaks, CA: Corwin Press

Pedro, J. (2005). Reflection in teacher education: exploring pre-service teachers? Meanings of reflective practice. Reflective Practice, 6, 49-66.

Peseta, T. (2007). Troubling our desires for research and writing within the academic development project. The International Journal for Academic Development, 12, 15-23.

Riessman, C. K. (2008). Narrative Methods for the Human Sciences. Thousands Oaks, California: Sage Publications.

Robertson, M. (2002). Quality and university teaching: juggling competing agendas, Quality in Higher Education, 8, 273-286.

Schön D (1983). The Reflective Practitioner. Basic Books: New York

Schön D., (1998). The Reflective Practitioner: How Professionals Think in Action. Ashgate: Brookfield.

Taylor, C. (1989). Sources of the Self: The Making of the Modern Identity. Cambridge: Cambridge University Press.

Watson, J.S. \& Wilcox, S. (2000). Reading for Understanding: Methods of reflecting practice, Reflective Practice, 1, 56-57

Weiner, L. (2007). A lethal threat to U.S. teacher education. Journal of Teacher Education, 58, 274-286.

Zembylas, M. (2007). Emotional ecology: The interaction of emotional knowledge and pedagogical content knowledge in teaching, Teaching and Teacher Education, 23, 355367.

Zeichner, K. (1994). Conceptions of reflective practice in teaching and teacher education. In G. Harvard \& P. Hodkinson (Eds.), Action and reflection in teacher education, pp. 114. Norwood, NJ: Ablex.

Word count: 5091 including references and abstract. 
